\title{
Magnetic Anisotropies in Rhombic Lanthanide(III) Complexes Do Not Conform to Bleaney's Theory
}

\author{
Goretti Castro $^{\mathrm{a}}$, Martín Regueiro-Figueroa ${ }^{\mathrm{b}}$, David Esteban-Gómez ${ }^{\mathrm{b}}$, Paulo Pérez-Lourido ${ }^{\mathrm{a}}$, Carlos \\ Platas-Iglesias ${ }^{* b}$, and Laura Valencia ${ }^{\mathrm{a}}$ \\ ${ }^{a}$ Departamento de Química Inorgánica, Facultad de Ciencias, Universidade de Vigo, As Lagoas, Pontevedra, \\ Marcosende 36310, Spain \\ ${ }^{\mathrm{b}}$ Centro de Investigaciones Científicas Avanzadas (CICA) and Departamento de Química Fundamental, \\ Universidade da Coruña, Campus da Zapateira-Rúa da Fraga 10,15008 A Coruña, Spain
}

This document is the Accepted Manuscript version of a Published Work that appeared in final form in Inorganic Chemistry, copyright $(\odot)$ American Chemical Society after peer review and technical editing by the publisher.

Inorganic Chemistry Volume 55, Issue 7, pages 3490-3497, April 4, 2016

Received: 21 December 2015, Published online: 15 March 2016, Published in print: 4 April 2016

\section{How to cite:}

Magnetic Anisotropies in Rhombic Lanthanide(III) Complexes Do Not Conform to Bleaney's Theory. Goretti Castro, Martín Regueiro-Figueroa, David Esteban-Gómez, Paulo Pérez-Lourido, Carlos PlatasIglesias, and Laura Valencia. Inorganic Chemistry $201655(7)$, 3490-3497. DOI: $\underline{10.1021 / a c s . i n o r g c h e m .5 b 02918}$

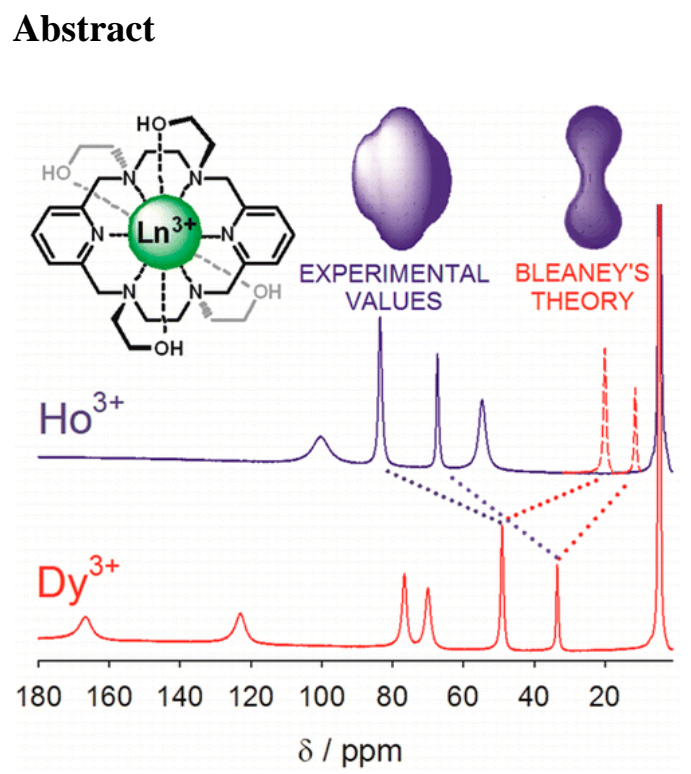

We report a complete set of magnetic susceptibilities of lanthanide complexes with a macrocyclic ligand based on a

3,6,10,13-tetraaza-1,8(2,6)-dipyridinacyclotetradecaphane platform containing four hydroxyethyl pendant arms $\left(\mathrm{L}^{1}\right)$. The $\left[\mathrm{LnL}^{1}\right]^{3+}$ complexes are isostructural along the lanthanide series from $\mathrm{Ce}^{3+}$ to $\mathrm{Yb}^{3+}$, with the only structural change observed along the series being the monotonous shortening of the Ln-donor distances due to lanthanide contraction. The ${ }^{1} \mathrm{H}$ NMR spectra point to a $D_{2}$ symmetry of the $\left[\mathrm{LnL}^{1}\right]^{3+}$ complexes in aqueous solution, which provides a unique opportunity for analysis of the rhombic magnetic anisotropies with an unequivocal location of the magnetic axes. The contact contributions for the observed paramagnetic shifts have been estimated with density functional theory calculations on the $\left[\mathrm{GdL}^{1}\right]^{3+}$ complex. Subsequently, the pseudocontact shifts could be factored out, thereby giving access to the axial and rhombic contributions of the magnetic susceptibility tensor. Our results show that the calculated magnetic anisotropies do not follow the trends predicted by Bleaney's theory, particularly in the case of $\mathrm{Ho}^{3+}$ and $\mathrm{Er}^{3+}$ complexes.

Keywords: contrast agents; coordination compounds; gadolinium; lanthanides; NMR imaging 


\section{Introduction}

The paramagnetic properties of trivalent lanthanide ions $\left(\mathrm{Ln}^{3+}\right)$ have been exploited in NMR for more than 4 decades. Complexes of the $\mathrm{Ln}^{3+}$ ions were widely used as shift reagents in the early times of NMR to reduce the complexity of second-order NMR spectra ${ }^{1}$ because the use of an appropriate paramagnetic shift reagent induces significant chemical shifts without provoking excessive line broadening. ${ }^{2}$ Shift reagents were particularly useful before high-field NMR spectrometers became routinely available. Later, chiral shift reagents were introduced in the analysis of mixtures of enantiomers and the assignment of an absolute configuration, ${ }^{3}$ an application that continues to be important nowadays. ${ }^{4}$ The paramagnetic shifts induced by $\mathrm{Ln}^{3+}$ were also intensively used for the determination of the structure and conformational properties of flexible molecules ${ }^{5}$ and proteins ${ }^{6}$ and of intra- and extracellular $\mathrm{Na}^{+}{ }^{7}$

The paramagnetic properties of $\mathrm{Gd}^{3+}$ associated with its ${ }^{8} \mathrm{~S}$ electronic ground state make this metal ion an ideal candidate for the preparation of contrast agents in magnetic resonance imaging. ${ }^{8}$ However, contrast agents based on the chemical exchange saturation transfer (CEST) approach represent an attractive alternative to the classical $\mathrm{Gd}^{3+}$-based agents. ${ }^{9}$ CEST agents contain a pool of exchangeable protons in intermediate-to-slow condition with bulk water $\left(k_{\mathrm{ex}} \leq \Delta \omega\right)$. Application of a presaturation pulse at the frequency of the exchangeable protons transfers some saturated spins into the water pool, which attenuates the signal of bulk water. ${ }^{9,10}$ Complexes of paramagnetic $\mathrm{Ln}^{3+}$ ions shift the resonance of the exchanging protons well away from the bulk water resonance, so that the exchange rate of the exchangeable protons $\left(k_{\mathrm{ex}}\right)$ can be faster while keeping the slow-to-intermediate exchange regime. ${ }^{10} \mathrm{~A}$ similar approach was used to generate the CEST effect by loading liposomes with paramagnetic $\mathrm{Ln}^{3+}$ complexes that shift the resonance of water molecules inside the liposome. ${ }^{11}$ Similarly, paramagnetic $\mathrm{Ln}^{3+}$ complexes have been used as chemical shift imaging reagents in vivo. ${ }^{12}$

The NMR signals due to ligand nuclei in paramagnetic $\mathrm{Ln}^{3+}$ complexes experience large frequency shifts as a result of both contact $\left(\delta_{i j}{ }^{\text {con }}\right)$ and pseudocontact $\left(\delta_{i j}{ }^{\text {sscon }}\right)$ contributions: ${ }^{13}$

$$
\delta_{\mathrm{ij}}^{\mathrm{para}}=\delta_{i j}^{\mathrm{exp}}-\delta_{i}^{\mathrm{dia}}=\delta_{i j}^{\mathrm{con}}+\delta_{i j}^{\mathrm{pscon}}
$$

where $\delta_{i j}{ }^{\text {para }}$ represents the paramagnetic shift induced by a lanthanide ion $j$ in a nucleus $i$ and $\delta_{i}{ }^{\text {dia }}$ accounts for the diamagnetic contribution. The pseudocontact contribution results from the local magnetic field induced in the nucleus under study by the magnetic moment of the $\mathrm{Ln}^{3+}$ ion and can be written as in eq 2 if the reference frame coincides with the main directions of the magnetic susceptibility tensor $\chi:^{13,14}$

$$
\delta_{i j}^{\mathrm{pscon}}=\frac{1}{12 \pi r^{3}}\left[\Delta \chi_{\mathrm{ax}}\left(\frac{3 z^{2}-r^{2}}{r^{2}}\right)+\frac{3}{2} \Delta \chi_{\mathrm{rh}}\left(\frac{x^{2}-y^{2}}{r^{2}}\right)\right]
$$

where $r=\sqrt{x^{2}+y^{2}+z^{2}}$, in which $x, y$, and $z$ are the Cartesian coordinates of a nucleus $i$ relative to the location of a $\mathrm{Ln}^{3+}$ ion $j$ placed at the origin, and $\Delta \chi_{\mathrm{ax}}$ and $\Delta \chi_{\mathrm{rh}}$ are the axial and rhombic parameters of the symmetric magnetic susceptibility tensor. For the special case of axial symmetry, which holds for systems containing a $C_{n}$ axis with $n \geq 3, D_{2}=0$. Bleaney ${ }^{15}$ proposed back in 1972 that the magnetic susceptibility tensor can be approximated in a power series of the inverse temperature. The first term in $T^{-1}$ described the isotropic magnetic susceptibility $\chi_{0}=1 / 3 T r$, while the terms in $T^{-2}$ correspond to the anisotropic part of the 
magnetic susceptibility, which Bleaney related to the conventional $B_{0}{ }^{2}$ and $B_{2}{ }^{2}$ crystal-field parameters of the second degree:

$$
\delta_{i j}^{\mathrm{pscon}}=C_{j} B_{0}^{2}\left(\frac{3 z^{2}-r^{2}}{r^{5}}\right)+\sqrt{6} C_{j} B_{2}^{2}\left(\frac{x^{2}-y^{2}}{r^{5}}\right)
$$

Here, $C_{j}$ are the so-called Bleaney factors, ${ }^{15}$ which are calculated as ${ }^{16,17}$

$$
C_{j}=\frac{-N_{\mathrm{A}} \beta^{2}\left(1+p_{j}\right) \xi_{j}}{60(k T)^{2}}
$$

where $\xi_{j}$ is a numerical factor characteristic of each $4 \mathrm{f}^{n}$ configuration and $1+p_{j}$ accounts for thermally populated excited states. Bleaney assumed that the energy of the crystal-field splitting created by the crystalfield parameters $B_{0}{ }^{2}$ and $B_{2}{ }^{2}$ is much smaller than $k T$, so that all crystal-field levels of the ground state possess similar populations. The validity of Bleaney's theory has been the subject of some debate. Deviations of pseudocontact shift patterns from Bleaney's theory have often been attributed to variations of the crystal-field parameters across the lanthanide series. ${ }^{18}$ Indeed, Binnemans and co-workers showed that Bleaney's approach does not provide a good quantitative approximation because it limits the temperature expansion of the magnetic susceptibility in the inverse temperature to $T^{-2}$ terms. ${ }^{19}$ More recently, the validity of the point electron-dipole approximation was also put into question. ${ }^{20}$ In a recent paper, Parker and coworkers have also shown that the pseudocontact shifts of axially symmetric $\mathrm{Ln}^{3+}$ complexes do not follow the trend expected from the respective $C_{j}$ values. ${ }^{21}$ However, Bertini and co-workers found that Bleaney's theory is in excellent qualitative agreement with the magnetic anisotropies obtained for the dicalcium protein $\mathrm{D}_{9 \mathrm{k}}$ incorporating the full series of $\mathrm{Ln}^{3+}$ ions into the C-terminal calcium binding site. ${ }^{22}$

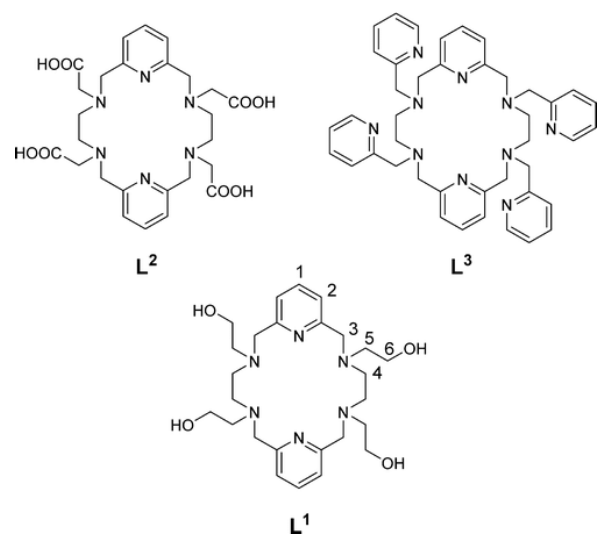

Chart 1. Ligands Discussed in the Present Work and the Numbering Scheme Used for NMR Spectral Assignment of the Complexes of $\mathrm{L}^{1}$

The magnetic anisotropy of $\mathrm{Ln}^{3+}$ complexes is a key property that in some cases leads to single-moleculemagnet behavior. ${ }^{23}$ Thus, understanding the factors that control the magnetic anisotropies of mononuclear 
$\mathrm{Ln}^{3+}$ complexes is important not only for the rational prediction of the paramagnetic NMR shifts induced by these metal ions but also in the field of molecular magnetism. ${ }^{24}$

Recently, we have shown that the macrocyclic ligand $\mathrm{L}^{1}$ (Chart 1 ) forms very inert complexes with the $\mathrm{Ln}^{3+}$ ions, while a detailed study of the structure in the solid state revealed 10-coordination of the metal ions by the ligand across the whole lanthanide series from lanthanum to lutetium. ${ }^{25}$ Furthermore, the intensity of the ${ }^{1} \mathrm{H}$ NMR signal of bulk water can be modulated by saturation of the signals of the hydroxyl protons of $\mathrm{Pr}^{3+}, \mathrm{Eu}^{3+}$, and $\mathrm{Yb}^{3+}$ complexes following CEST mechanisms. ${ }^{25}$ Herein, the validity of Bleaney's theory is assessed by analyzing the ${ }^{1} \mathrm{H}$ NMR spectra of the whole series of paramagnetic $\mathrm{Ln}^{3+}$ ions from $\mathrm{Ce}^{3+}$ to $\mathrm{Yb}^{3+}$ (except $\mathrm{Pm}^{3+}$ and $\mathrm{Gd}^{3+}$ ). The $\left[\mathrm{LnL}^{1}\right]^{3+}$ complexes represent ideal candidates for this purpose because (i) they provide a complete set of isostructural complexes and experimental shifts throughout the series ${ }^{26}$ and (ii) the $\left[\mathrm{LnL}^{1}\right]^{3+}$ complexes present $D_{2}$ symmetry in solution, which provides an unequivocal location of the magnetic axes.

\section{Results}

\section{${ }^{1}$ H NMR Shifts of Paramagnetic $\left[\operatorname{LnL}^{1}\right]^{3+}$ Complexes}

The NMR spectra of paramagnetic $\left[\mathrm{LnL}^{1}\right]^{3+}$ complexes $(\mathrm{Ln}=\mathrm{Ce}-\mathrm{Yb}$, except $\mathrm{Pm}$ and $\mathrm{Gd})$ were recorded in a $\mathrm{D}_{2} \mathrm{O}$ solution at $25{ }^{\circ} \mathrm{C}$ and $\mathrm{pH}$ 7.0. The spectra of the complexes with $\mathrm{Pr}^{3+}$ and $\mathrm{Yb}^{3+}$ were presented in a previous paper, and the observed paramagnetic shifts were analyzed assuming a pseudocontact model. ${ }^{25}$ All ${ }^{1} \mathrm{H}$ NMR spectra present 10 signals, which points to a $D_{2}$ symmetry of the complexes in solution, as observed previously for the $\mathrm{Pr}^{3+}, \mathrm{Eu}^{3+}$, and $\mathrm{Yb}^{3+}$ analogues. The representative spectra of the $\mathrm{Dy}^{3+}$ and $\mathrm{Ho}^{3+}$ complexes are presented in Figure 1, while chemical shift data of $\left[\mathrm{LnL}^{1}\right]^{3+}$ complexes are provided in Table 1. A full attribution of the ${ }^{1} \mathrm{H}$ NMR signals for each $\left[\mathrm{LnL}^{1}\right]^{3+}$ complex could be achieved: (i) by comparison to the assignments made to the $\mathrm{Yb}^{3+}$ and $\mathrm{Pr}^{3+}$ complexes; (ii) on the basis of the crosspeaks observed in the COSY spectra of $\mathrm{Ce}^{3+}, \mathrm{Pr}^{3+}, \mathrm{Nd}^{3+}, \mathrm{Sm}^{3+}, \mathrm{Eu}^{3+}$, and $\mathrm{Yb}^{3+}$ complexes (see the Supporting Information); (iii) by using line-width analysis because the paramagnetic contribution to the observed line widths is proportional to $1 / r^{6}$, where $r$ represents the distance between the observed nucleus and the paramagnetic $\mathrm{Ln}^{3+}$ ion. ${ }^{27}$ This allowed a straightforward assignment of the signals due to protons H5ax, which show particularly short Ln $\cdots H$ distances [3.46-3.49 $\AA$ according to our density functional theory (DFT) calculations]. Line-width analysis also allowed one to identify axial and equatorial protons because the former are generally closer to the $\mathrm{Ln}^{3+}$ ion, with the noticeable exception of the H6ax and H6eq protons, which present very similar $\mathrm{Ln} \cdots \mathrm{H}$ distances and thus line widths.

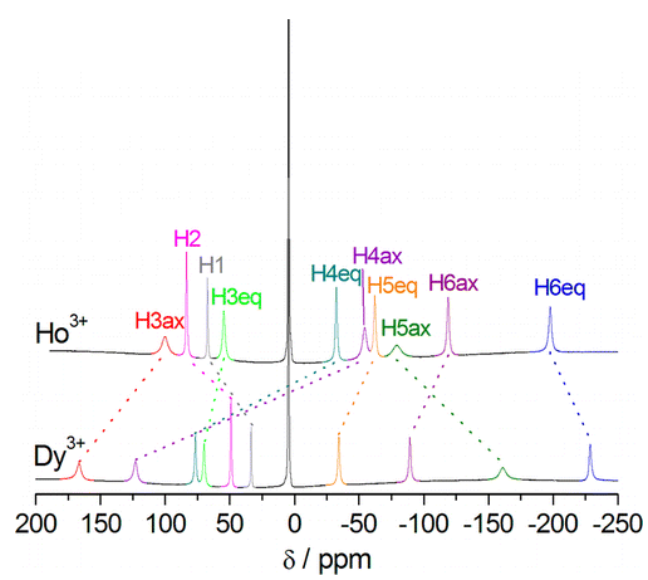

Figure 1. ${ }^{1} \mathrm{H}$ NMR spectra of the $\left[\mathrm{LnL}^{1}\right]^{3+}$ complexes $(\mathrm{Ln}=\mathrm{Dy}, \mathrm{Ho})$ recorded in a $\mathrm{D}_{2} \mathrm{O}$ solution at $25^{\circ} \mathrm{C}(\mathrm{pH} 7.0,400 \mathrm{MHz})$. 
Table 1. ${ }^{1} \mathrm{H}$ NMR Shifts $\left(\mathrm{D}_{2} \mathrm{O}, 25^{\circ} \mathrm{C}, \mathrm{pH} 7.0,400 \mathrm{MHz}\right)$ Observed for $\left[\mathrm{LnL}^{1}\right]^{3+}$ Complexes

\begin{tabular}{lllllllllll}
\hline & H1 & H2 & H3ax & H3eq & H4ax & H4eq & H5ax & H5eq & H6ax & H6eq \\
\hline $\mathrm{Ce}$ & 8.50 & 8.32 & 14.17 & 9.63 & 16.30 & 13.99 & -8.80 & 2.68 & 3.24 & -8.17 \\
$\mathrm{Pr}^{\mathrm{a}}$ & 9.35 & 10.26 & 22.88 & 16.60 & 25.97 & 25.97 & -18.12 & 5.43 & 1.12 & -19.90 \\
$\mathrm{Nd}$ & 14.62 & 16.17 & 15.14 & 16.17 & 1.06 & 12.08 & -7.56 & 1.86 & -4.22 & -18.80 \\
$\mathrm{Sm}$ & 8.41 & 8.14 & 7.36 & 4.82 & 4.92 & 2.90 & 0.50 & -0.27 & 2.25 & 1.54 \\
$\mathrm{Eu}$ & 1.45 & -2.18 & -12.00 & -17.43 & -1.85 & -21.20 & 18.74 & -3.51 & 10.59 & 33.58 \\
$\mathrm{~Tb}$ & 14.95 & 25.51 & 148.35 & 48.10 & 148.35 & 78.30 & -146.97 & -25.32 & -61.00 & -178.49 \\
$\mathrm{Dy}$ & 33.48 & 49.06 & 166.72 & 70.00 & 122.98 & 76.64 & -161.06 & -34.18 & -89.19 & -228.64 \\
$\mathrm{Ho}$ & 67.30 & 83.46 & 100.29 & 54.68 & -54.20 & -32.39 & -79.09 & -62.02 & -118.82 & -197.78 \\
$\mathrm{Er}$ & 52.00 & 57.74 & -6.40 & 3.50 & -138.40 & -95.84 & 32.51 & -44.60 & -44.60 & -64.28 \\
$\mathrm{Tm}$ & -9.25 & -18.65 & -83.39 & -54.96 & -53.52 & -49.12 & 92.57 & 14.46 & 49.28 & 139.15 \\
$\mathrm{Yb}$ & -4.69 & -9.43 & -33.84 & -19.77 & -9.05 & -12.79 & 41.87 & 14.11 & 31.65 & 70.34 \\
$\mathrm{~A} / \hbar\left(\mathrm{rad} \mathrm{s}^{-1}\right)$ & -0.0407 & -0.02413 & 0.08105 & -0.4136 & 0.00898 & -0.6622 & 0.02111 & -0.31956 & -0.23895 & 0.10260 \\
\hline
\end{tabular}

${ }^{a}$ Data taken from ref 25. HFCCs calculated for $\left[\mathrm{GdL}^{1}\right]^{3+}$ at the DKH2/Neese/EPR-III level.

\section{Assessment of the Contact Contributions}

The contact shift caused by a $\mathrm{Ln}^{3+}$ ion $j$ in a nucleus $i\left(\delta_{i j}{ }^{\text {con }}\right)$ arises from through-bond transmission of an unpaired electron-spin density from the metal ion to the observed nucleus and can be approximated by eq $5:^{14}$

$$
\delta_{i j}^{\text {con }}=\left\langle S_{z}\right\rangle_{j} \frac{\mu_{\mathrm{B}}}{3 k T \gamma_{\mathrm{I}}} \frac{A}{\hbar} \times 10^{6}
$$

where $\left\langle S_{z}\right\rangle_{j}$ represents the reduced value of the average spin polarization, $\mu_{\mathrm{B}}$ is the Bohr magneton, $k$ is the Boltzmann constant, $\gamma_{\mathrm{I}}$ is the gyromagnetic ratio of the observed nucleus, $A / \hbar$ is the hyperfine coupling constant (HFCC, in $\mathrm{rad} \cdot \mathrm{s}^{-1}$ ), and $\delta_{i j}{ }^{\text {con }}$ is expressed in $\mathrm{ppm}$. The values of $\left\langle S_{z}\right\rangle_{j}$ calculated for the different $\mathrm{Ln}^{3+}$ ions ${ }^{28}$ are given in Table 2, together with the Bleaney factors $C_{j}{ }^{29}$ Inspection of eqs 3 and 5 shows that the relative weight of contact and pseudocontact contributions for a given $\mathrm{Ln}^{3+}$ ion should follow the $\left\langle S_{z}\right\rangle_{j} / C_{j}$ ratio. Thus, good fits according to the pseudocontact model are expected for $\mathrm{Yb}^{3+}, \mathrm{Tm}^{3+}, \mathrm{Ce}^{3+}$, or $\mathrm{Dy}^{3+}$, which present $\left\langle S_{z}\right\rangle_{j} / C_{j}$ ratios $<0.3$. On the contrary, poor fits can be anticipated for $\mathrm{Nd}^{3+}$ and $\mathrm{Eu}^{3+}{ }^{30}$

The $\delta_{i j}$ para values of $\left[\mathrm{LnL}^{1}\right]^{3+}$ complexes were estimated by using the ${ }^{1} \mathrm{H}$ NMR chemical shifts of the diamagnetic $\mathrm{Lu}^{3+}$ complex as a reference. The paramagnetic shifts were then initially analyzed according to a pseudocontact model with eq 2. As structural models, we have used optimized geometries obtained with DFT calculations performed in aqueous solution at the TPSSh/LCRECP/6-31G(d,p) level (Figure 2; see the computational details below). According to our calculations, the Ln-donor distances decrease across the lanthanide series following a quadratic trend, as expected for an isostructural series of $\mathrm{Ln}^{3+}$ complexes 
(Figures S15 and S16, Supporting Information). ${ }^{31,32}$ The quality of the agreement between the experimental and calculated shifts was assessed by using the $\mathrm{AF}_{j}$ factor defined $\mathrm{as}^{33}$

$$
\mathrm{AF}_{j}=\left[\sum_{i}\left(\delta_{i}^{\mathrm{exp}}-\delta_{i}^{\mathrm{cal}}\right)^{2} / \sum_{i}\left(\delta_{i}^{\mathrm{exp}}\right)^{2}\right]^{1 / 2}
$$

where $\delta_{i}{ }^{\text {exp }}$ represent the pseudocontact shifts obtained from the observed $\delta_{i j}{ }^{\text {para }}$ values by subtracting the contact contribution, while $\delta_{i}{ }^{\text {cal }}$ represent the pseudocontact shifts calculated with eq 2 . This analysis was found in our previous paper to provide a satisfactory agreement, neglecting contact contributions for $\mathrm{Yb}^{3+}\left(\mathrm{AF}_{j}=0.044\right)$, while for $\mathrm{Pr}^{3+}$, the agreement factor was considerably higher $\left(\mathrm{AF}_{j}=0.112\right)$. The data presented in Table 2 show that the best agreement according to the pseudocontact model is provided by $\mathrm{Ln}^{3+}$ with high $C_{j} /\left\langle S_{z}\right\rangle_{j}$ ratios, while unacceptable $\mathrm{AF}_{j}$ values are obtained for $\mathrm{Nd}^{3+}$ and $\mathrm{Eu}^{3+}$. These results clearly show that contact shifts provide important contributions to the overall paramagnetic shifts observed for several $\left[\mathrm{LnL}^{1}\right]^{3+}$ complexes.

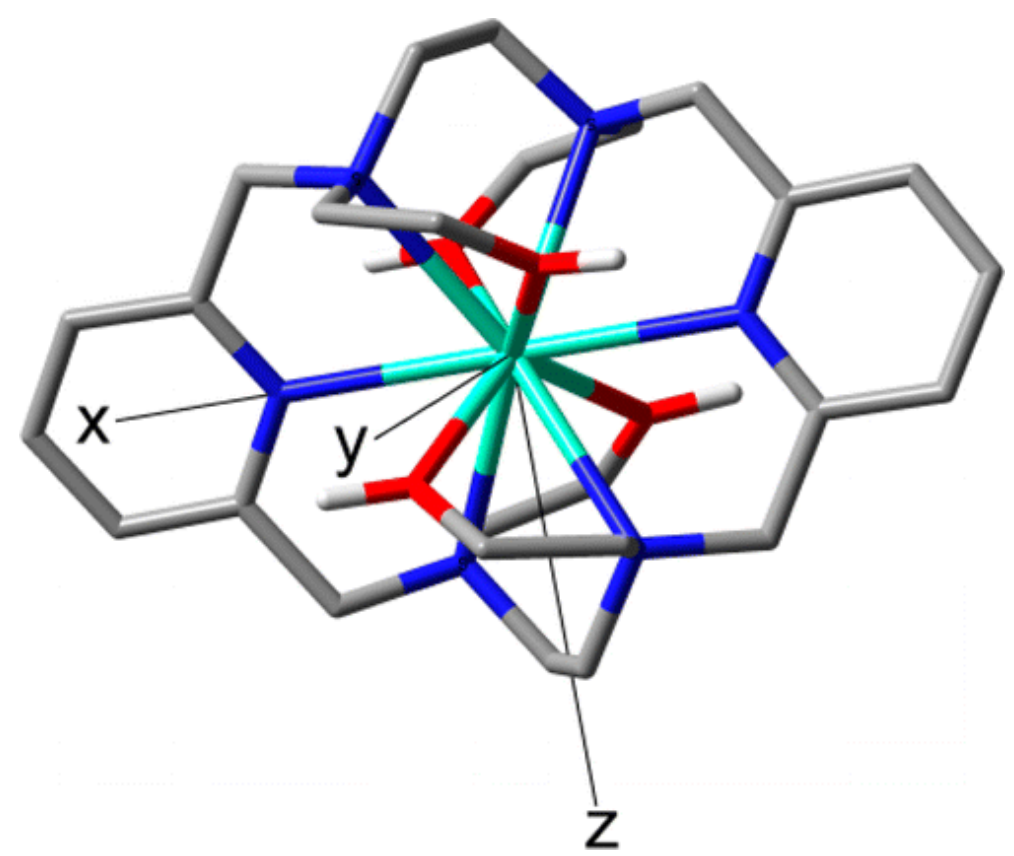

Figure 2. Structure of the $\left[\mathrm{EuL}^{1}\right]^{3+}$ complex optimized in aqueous solution at the TPSSh/LCRECP/6-31G(d,p) level and orientation of the magnetic axes used in analysis of the pseudocontact shifts. H atoms, except those of hydroxyl protons, have been omitted for simplicity.

The isotropic HFCCs $A / \hbar$ responsible for the contact shifts in $\mathrm{Ln}^{3+}$ complexes (eq 5) are the result of the Fermi contact interaction and depend on the difference between the majority spin $(\alpha)$ and minority spin $(\beta)$ densities at the position of the nucleus $i\left[\rho^{\alpha-\beta}\left(R_{i}\right)\right]$ as expressed in eq $7:^{34}$

$$
\frac{A}{\hbar}=\frac{8 \pi^{2}}{3 \mathrm{~S}} \beta_{\mathrm{e}} \beta_{\mathrm{N}} g_{\mathrm{e}} g_{\mathrm{N}} \rho^{\alpha-\beta}\left(R_{i}\right)
$$


where $\beta_{\mathrm{N}}$ and $\beta_{\mathrm{e}}$ are the nuclear and Bohr magnetons, respectively, $g_{\mathrm{N}}$ and $g_{\mathrm{e}}$ are the nuclear and freeelectron $g$ values, and $S$ is the total electron spin of the system. In a previous work, we have shown that allelectron relativistic DFT calculations based on the second-order Douglas-Kroll-Hess (DKH2) method (DKH2/Neese/EPR-III) provide accurate $A / \hbar$ values for different $\mathrm{Gd}^{3+}$ complexes. ${ }^{35,36}$ Similar calculations performed for $\left[\mathrm{GdL}^{1}\right]^{3+}$ provide the HFCCs listed in Table 1 . The calculated $A / \hbar$ values present different signs depending on the nucleus under consideration, which shows that the spin-density distribution is dominated by the spin-polarization mechanism, which is the result of an effective attraction of unpaired electrons to the nearby ones of the same spin. ${ }^{37}$ The proton nuclei of the pyridyl units $\mathrm{H} 1$ and $\mathrm{H} 2$ present very low calculated $A / \hbar$ values because they are rather far away from the metal center in terms of the number of bonds. Important negative $A / \hbar$ values are calculated for the equatorial protons of the ligands $\mathrm{H} 3-\mathrm{H} 6$, while the axial protons present positive HFCCs with smaller absolute values. These results are in line with our previous calculations, which showed that the $A / \hbar$ values are very sensitive to the $\mathrm{H}-\mathrm{C}-\mathrm{X}-\mathrm{Gd}$ dihedral angle $(\mathrm{X}=\mathrm{N}$ or $\mathrm{O}){ }^{36}$

Table 2. Values of $C_{j}$ at Room Temperature, Values of $\left\langle S_{z}\right\rangle$ and Effective $\left\langle S_{z}\right\rangle\left(\left\langle S_{z}\right\rangle^{\text {eff }}\right)$ Values, Axial $\left(\Delta \chi_{\text {ax }}\right)$ and Rhombic $\left(\Delta \chi_{\mathrm{rh}}\right)$ Magnetic Susceptibilities, and Agreement Factors $\left(\mathrm{AF}_{j}\right)$ Obtained from Analysis of the Paramagnetic ${ }^{1} \mathrm{H}$ NMR Shifts of $\left[\mathrm{LnL}^{1}\right]^{3+}$ Complexes

\begin{tabular}{|c|c|c|c|c|c|c|c|}
\hline & $\mathrm{C}_{\mathrm{j}}^{\mathrm{a}}$ & $\left\langle\mathbf{S}_{\mathbf{z}}\right\rangle^{\mathbf{b}}$ & $\left\langle\mathbf{S}_{z}\right\rangle^{\text {eff } \mathrm{c}}$ & $\Delta \chi_{\mathrm{ax}} \times 10^{-32} \mathrm{~m}^{3 \mathrm{~d}}$ & $\Delta \chi_{\mathrm{rh}} \times 10^{-32} \mathrm{~m}^{3 \mathrm{~d}}$ & $\mathbf{A F}_{\mathrm{j}}{ }^{\mathrm{e}}$ & $\mathrm{AF}_{\mathrm{j}}{ }^{\mathrm{f}}$ \\
\hline $\mathrm{Ce}$ & -6.3 & -0.974 & -0.037 & $-1.97 \pm 0.05$ & $-1.68 \pm 0.08$ & 0.0770 & 0.0770 \\
\hline $\operatorname{Pr}$ & -11.0 & -2.956 & -2.370 & $-3.59 \pm 0.02$ & $-2.76 \pm 0.05$ & 0.1115 & 0.0452 \\
\hline $\mathrm{Nd}$ & -4.2 & -4.452 & -3.577 & $-0.32 \pm 0.03$ & $-4.21 \pm 0.04$ & 0.2415 & 0.0507 \\
\hline $\mathrm{Sm}$ & -0.7 & 0.06 & $\mathrm{~g}$ & $\mathrm{~g}$ & $\mathrm{~g}$ & $\mathrm{~g}$ & $\mathrm{~g}$ \\
\hline $\mathrm{Eu}$ & 4.0 & 10.68 & 10.06 & $1.20 \pm 0.04$ & $4.75 \pm 0.06$ & 0.4370 & 0.0577 \\
\hline $\mathrm{Tb}$ & -86 & 31.853 & 22.01 & $-22.5 \pm 0.2$ & $-23.1 \pm 0.3$ & 0.1505 & 0.0418 \\
\hline Dy & -100 & 28.565 & 15.88 & $-20.1 \pm 0.2$ & $-33.2 \pm 0.3$ & 0.1013 & 0.0335 \\
\hline Ho & -39 & 22.642 & 11.44 & $3.1 \pm 0.2$ & $-39.7 \pm 0.3$ & 0.0940 & 0.0429 \\
\hline Er & 33 & 15.382 & 6.079 & $17.3 \pm 0.2$ & $-18.3 \pm 0.3$ & 0.0988 & 0.0732 \\
\hline $\mathrm{Tm}$ & 53 & 8.210 & 4.710 & $9.6 \pm 0.2$ & $19.5 \pm 0.2$ & 0.0697 & 0.0500 \\
\hline $\mathrm{Yb}$ & 22 & 2.589 & 1.371 & $2.74 \pm 0.05$ & $10.57 \pm 0.07$ & 0.0449 & 0.0321 \\
\hline
\end{tabular}

${ }^{\mathrm{a}}$ Values at $300 \mathrm{~K}$ scaled to -100 for Dy taken from ref 29. ${ }^{\mathrm{b}}$ From ref $28 .{ }^{\mathrm{c}}$ Effective $\left\langle S_{z}\right\rangle$ values obtained from analysis of the paramagnetic shifts (see the text). ${ }^{\mathrm{d}}$ Axis orentations are defined according to Figure $2 .{ }^{\mathrm{e}}$ Neglecting

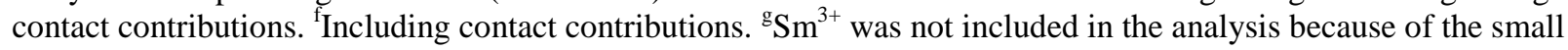
paramagnetic shifts induced by this ion.

\section{Analysis of the ${ }^{1} \mathrm{H}$ NMR Paramagnetic Shifts Including Contact Contributions}

The $A / \hbar$ values obtained with the aid of DFT calculations can be used to estimate the contact contributions of each ligand nuclei with eq 5 and the $\left\langle\mathrm{S}_{z}\right\rangle$ values available in the literature. ${ }^{28}$ This approach was successfully applied to analyze the paramagnetic ${ }^{1} \mathrm{H}$ NMR shifts of different $\mathrm{Tb}^{3+}$ complexes, including $\left[\mathrm{TbL}^{2}\right]^{-}$and $\left[\mathrm{TbL}^{3}\right]^{3+}$ (Chart 1). ${ }^{36}$ Subsequently, the pseudocontact contributions can be obtained by subtracting the contact contributions from the overall paramagnetic shifts (eq 1). In the case of $\left[\mathrm{TbL}^{2}\right]^{-}$, the pseudocontact shifts obtained by using this methodology were found to be in good agreement with those obtained by 
Berardozzi and Di Bari using a completely different approach. ${ }^{38}$ Our initial analysis of the paramagnetic shifts observed for $\left[\mathrm{TbL}^{1}\right]^{3+}$ afforded similar results because the agreement factor improved noticeably upon the inclusion of contact shifts. However, this preliminary analysis also showed that the use of $\left\langle S_{z}\right\rangle$ values somewhat different from those reported in the literature resulted in better agreement factors. This is illustrated for the representative $\left[\mathrm{PrL}^{1}\right]^{3+}$ and $\left[\mathrm{DyL}^{1}\right]^{3+}$ complexes in Figure 3 . Thus, for each $\left[\mathrm{LnL}^{1}\right]^{3+}$ complex, the paramagnetic shifts were analyzed by varying $\left\langle S_{z}\right\rangle$ around the tabulated values and calculating the agreement factors $\mathrm{AF}_{j}$ at each point. The plots of $\mathrm{AF}_{j}$ versus $\left\langle S_{z}\right\rangle$ were subsequently fitted to a fourth-degree polynomial function, which presents a minimum that provides an effective $\left\langle S_{z}\right\rangle$ value $\left(\left\langle S_{z}\right\rangle^{\text {eff }}\right)$, giving the best agreement between the experimental and calculated paramagnetic ${ }^{1} \mathrm{H}$ NMR shifts (Table 2). An important improvement of the agreement factors was observed for all $\mathrm{Ln}^{3+}$ ions upon the inclusion of contact contributions, with the exception of $\mathrm{Ce}^{3+}$, which provided an $\left\langle S_{z}\right\rangle^{\text {eff }}$ value very close to zero (Table 2). The agreement factors obtained upon the inclusion of contact contributions are very good, ranging from 0.032 for $\mathrm{Yb}^{3+}$ to 0.077 for $\mathrm{Ce}^{3+}$. Obviously, a particularly important improvement of the agreement between the experimental and calculated paramagnetic shifts is observed for those complexes with important contact shifts such as $\left[\mathrm{EuL}^{1}\right]^{3+}$. This becomes evident by comparing the absolute differences between the experimental and calculated paramagnetic shifts $(\Delta \delta)$ with and without the inclusion of contact shifts (Figure 4). Neglecting the contact contribution results in very large deviations of the experimental and calculated shifts (up to $13.1 \mathrm{ppm}$ ), noticeably in the case of equatorial protons. Considering the contact contributions in the analysis of the paramagnetic shifts reduces the $\Delta \delta$ values to $0.04-1.72 \mathrm{ppm}$.

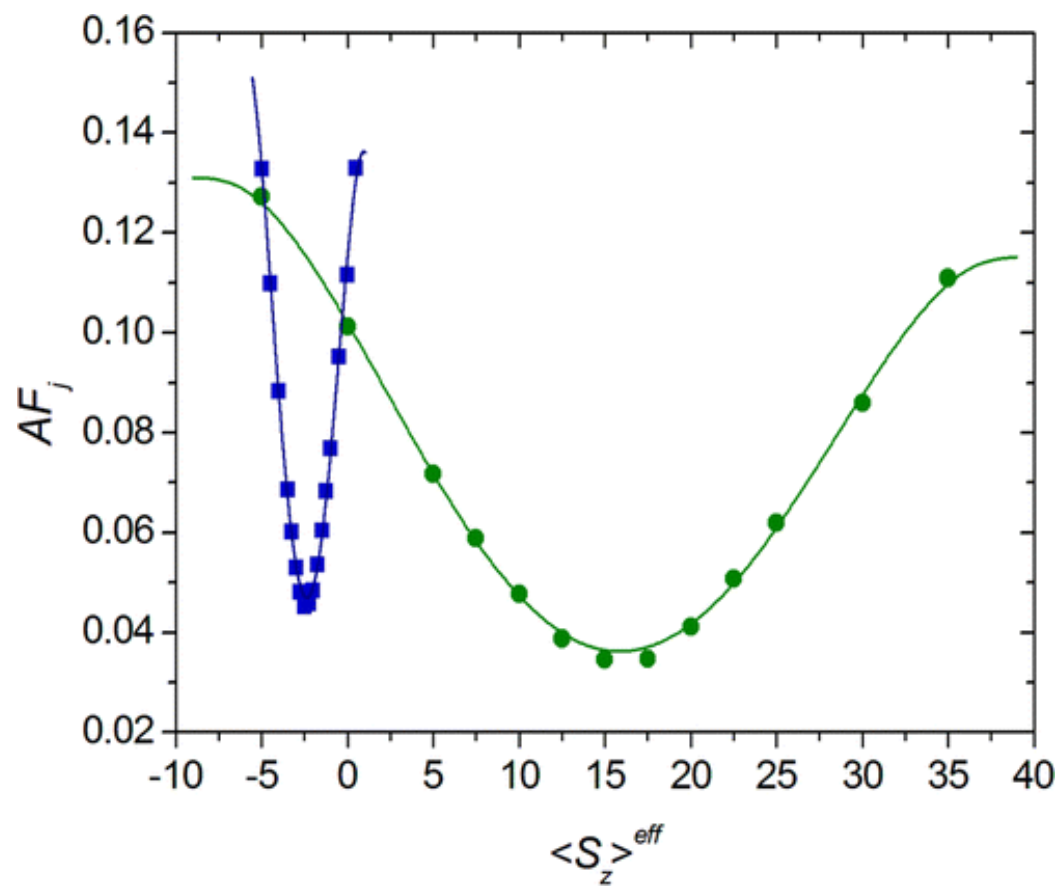

Figure 3. Plot of the agreement factor $\mathrm{AF}_{j}$ versus the effective $\left\langle S_{z}\right\rangle$ value used in analysis of the ${ }^{1} \mathrm{H}$ NMR paramagnetic shifts of $\left[\mathrm{PrL}^{1}\right]^{3+}$ (squares) and $\left[\mathrm{DyL}^{1}\right]^{3+}$ (circles). The solid lines represent the fit of the data with minima at $\left\langle S_{z}\right\rangle^{\text {eff }}$ of -2.37 (Pr) and 15.88 (Dy).

The calculated $\left\langle S_{z}\right\rangle^{\text {eff }}$ values (Table 2) deviate significantly from those reported in the literature for most of the $\mathrm{Ln}^{3+}$ ions. These differences could arise from the inaccuracy of the $\left\langle S_{z}\right\rangle$ values available in the literature, which were obtained by neglecting the ligand-field splitting of the $J$ manifold, ${ }^{37}$ but could also be the result of errors in the $A / \hbar$ values obtained with our DFT calculations, changes in the HFCCs along the lanthanide series, or a combination of these three factors. Whatever the reasons for these deviations, the $\left\langle S_{z}\right\rangle$ values 
obtained for $\left[\mathrm{LnL}^{1}\right]^{3+}$ complexes and the theoretical values provide a rather good linear correlation $\left(R^{2}>0.98\right.$; Figure S14, Supporting Information), which provides support to our methodology.

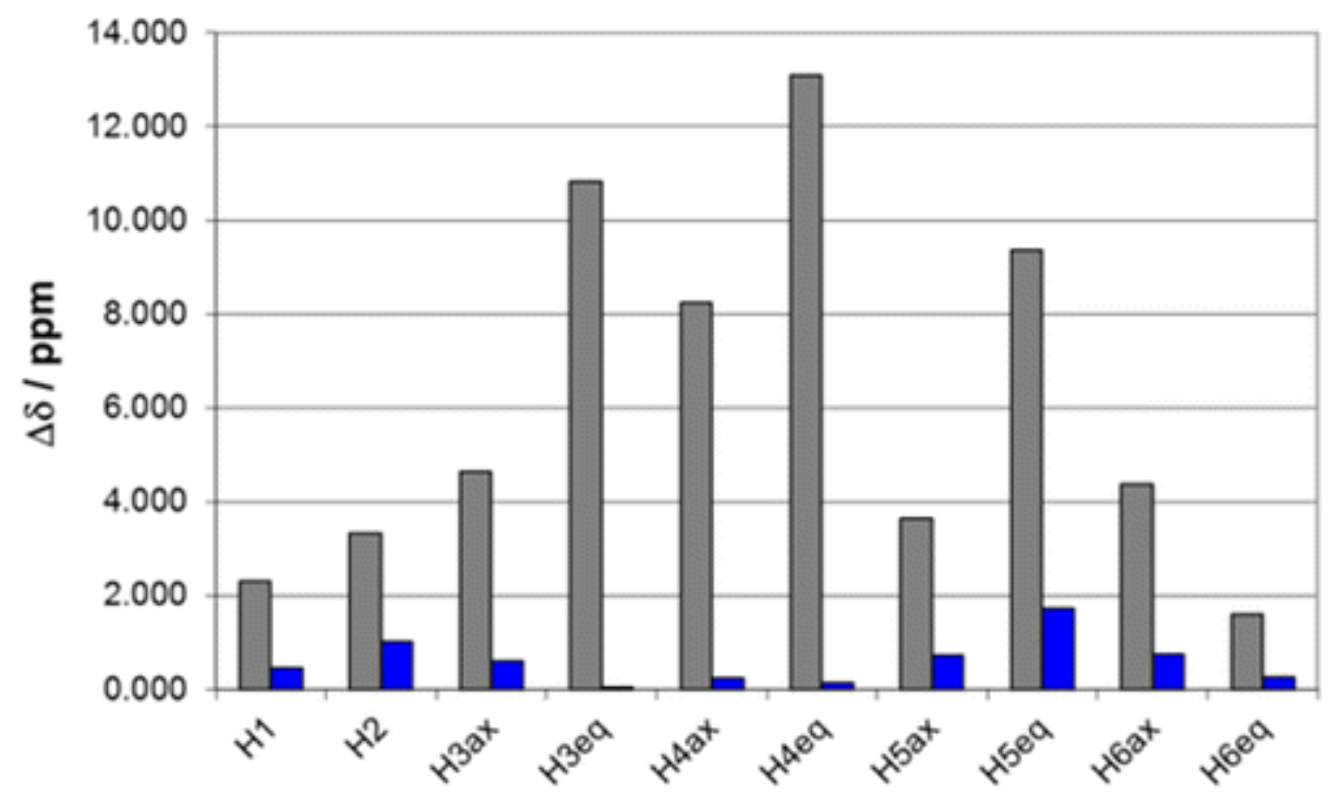

Figure 4. Absolute deviations $(\Delta \delta)$ of experimental and calculated $\mathrm{Eu}^{3+}$-induced ${ }^{1} \mathrm{H}$ NMR shifts in $\left[\mathrm{EuL}^{1}\right]^{3+}$. Color code: gray, neglecting contact contributions; blue, including contact contributions.

\section{Analysis of the Magnetic Anisotropy}

Analysis of the paramagnetic ${ }^{1} \mathrm{H}$ NMR shifts of $\left[\mathrm{LnL}^{1}\right]^{3+}$ complexes provides axial $\left(\Delta \chi_{\mathrm{ax}}\right)$ and rhombic $\left(\Delta \chi_{\mathrm{rh}}\right)$ anisotropies of the magnetic susceptibility tensor. Assuming that the magnetic axes coincide with the three $C_{2}$ symmetry axes of the molecule, analysis of the pseudocontact shifts according to eq 2 still yields six degenerate solutions that correspond to the six different orientations of the magnetic axes. For each of these solutions, the calculated shifts (and thus agreement factors $\mathrm{AF}_{j}$ ) are identical, but the values of $\Delta \chi_{\mathrm{ax}}$ and $\Delta \chi_{\mathrm{rh}}$ are different. Thus, we have taken the arbitrary orientation of the principal axes of the magnetic susceptibility tensor shown in Figure 2, which provides the $\Delta \chi_{\mathrm{ax}}$ and $\Delta \chi_{\mathrm{rh}}$ values listed in Table 2.

The magnetic anisotropies calculated for $\left[\mathrm{LnL}^{1}\right]^{3+}$ complexes follow the qualitative trends predicted by Bleaney's theory for most of the lanthanide ions, with the noticeable exceptions of $\mathrm{Ho}^{3+}$ and $\mathrm{Er}^{3+}$. Indeed, the $C_{j}$ value reported for $\mathrm{Ho}^{3+}(-39)$ has the same sign as those of $\mathrm{Tb}^{3+}(-86)$ and $\mathrm{Dy}^{3+}(-100)$, and therefore the $\Delta \chi_{\mathrm{ax}}$ and $\Delta \chi_{\mathrm{rh}}$ values characterizing the magnetic anisotropies of these complexes should have identical signs. However, this is not the case. This anomalous behavior can already be noticed by a simple inspection of the spectra shown in Figure 1. Indeed, according to Bleaney's constants, the paramagnetic shifts of the $\mathrm{Ho}^{3+}$ complex should amount to about $39 \%$ of those observed for the $\mathrm{Dy}^{3+}$ analogue. However, certain proton signals observed for $\left[\mathrm{HoL}^{1}\right]^{3+}$ present larger shifts compared with $\left[\mathrm{DyL}^{1}\right]^{3+}$ (i.e., $\mathrm{H} 1$ and $\mathrm{H} 2$, which can be unequivocally assigned on the basis of their integration and line widths), and furthermore the signs of some of the resonances are reversed. A comparison of the spectra recorded for the $\mathrm{Er}^{3+}, \mathrm{Tm}^{3+}$, and $\mathrm{Yb}^{3+}$ complexes also reveals the anomalous behavior of the $\mathrm{Er}^{3+}$ complex. Plots of Bleaney's factors versus the $\Delta \chi_{\mathrm{ax}}$ and $\Delta \chi_{\text {rh }}$ values provide reasonably good linear correlations when $\mathrm{Ho}^{3+}$ and $\mathrm{Er}^{3+}$ are excluded from the fit (Figure 5) but clearly highlight that the latter two metal ions do not follow the trend expected according to Bleaney's theory. 

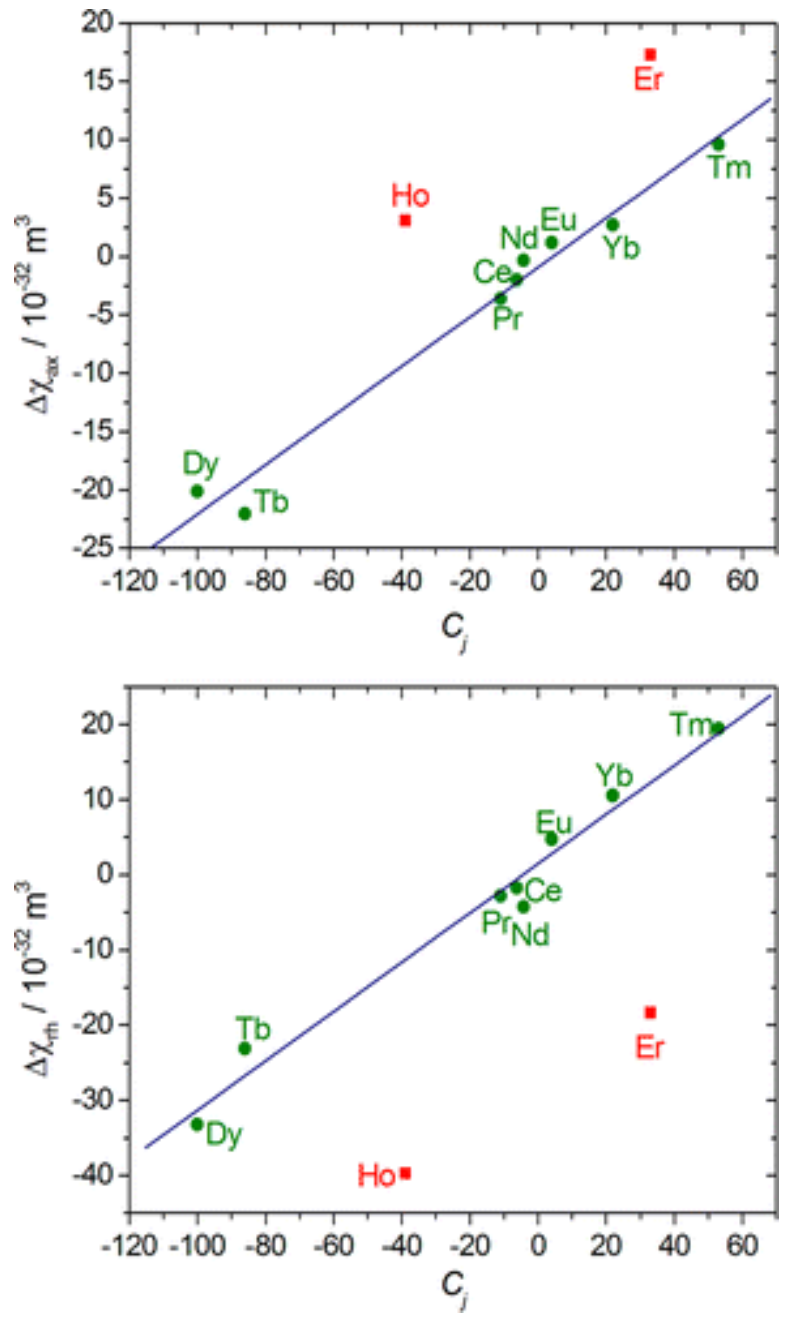

Figure 5. Plots of Bleaney's factors $C_{j}$ versus the $\Delta \chi_{\mathrm{ax}}$ and $\Delta \chi_{\mathrm{rh}}$ values obtained for [ $\left[\mathrm{LnL}^{1}\right]^{3+}$ complexes. The solid lines correspond to linear fits of the data $\left(R^{2}>0.988\right)$ excluding $\mathrm{Ho}^{3+}$ and $\mathrm{Er}^{3+}$.

\section{Discussion and Conclusions}

The present contribution has shown that the paramagnetic ${ }^{1} \mathrm{H}$ NMR shifts of $\left[\mathrm{LnL}^{1}\right]^{3+}$ complexes do not follow the trend expected according to Bleaney's factors. The validity of this theory has been the subject of debate during the last 15 years. In particular, Bleaney assumed that the ligand-field splitting is smaller than $k T$, so that the crystal-field levels of the ground multiplet should have comparable populations at room temperature. The assumption was questioned by Binnemans and co-workers using numerical simulations of the magnetic anisotropies of lanthanide complexes considering different coordination numbers and coordination polyhedra. ${ }^{19}$ These simulations predicted that for most coordination polyhedra the signs of the magnetic anisotropy should follow the trends predicted by Bleaney, with the noticeable exceptions of coordination polyhedra in which rank-two crystal-field parameters are small or zero. In such cases, the sign of the magnetic anisotropy could be irregular. The results obtained in this study provide experimental evidence for the behavior predicted by Binnemans and co-workers, and later suggested by Parker and coworkers from analysis of the shifts observed for pyridyl protons located at least four bonds away from the metal ion $(\mathrm{Ln}=\mathrm{Tb}-\mathrm{Yb}){ }^{21}$

The study presented in this paper allowed us to calculate a reliable set of magnetic anisotropies for all paramagnetic rhombic $\left[\mathrm{LnL}^{1}\right]^{3+}$ complexes (except Pm and Gd), which required an accurate estimation of the contact contributions to the paramagnetic shifts. This was achieved in the past by using the Reilley 
method, ${ }^{39}$ which allows the separation of contact and pseudocontact contributions relying on several assumptions: (i) A series of complexes is isostructural along the lanthanide series. (ii) The Bleaney constants $C_{j}$ and spin expectation values $\left\langle S_{z}\right\rangle$ do not differ significantly from the tabulated values. (iii) The crystal-field parameters and HFCCs do not change across the lanthanide series. The Reilley method was, however, shown to perform poorly for complexes that did not show important structural changes across the series, such as, for instance, the $\left[\mathrm{LnL}^{2}\right]^{-}$and $[\mathrm{Ln}(\mathrm{DPA})]^{3-}(\mathrm{DPA}=2,6$-dipicolinate $)$ derivatives. ${ }^{40,41}$ Another notable example was provided recently with analysis of the magnetic anisotropy in endohedral nitride clusterfullerenes, which revealed remarkable deviations from the linear trends expected according to the Reilley method for $\mathrm{Tb}^{3+}$ and $\mathrm{Tm}^{3+}{ }^{42}$ Application of the Reilley method to the $\left[\mathrm{LnL}^{1}\right]^{3+}$ complexes results in plots of $\delta_{i j}$ para $/\left\langle S_{z}\right\rangle_{j}$ versus $C_{j} /\left\langle S_{z}\right\rangle_{j}$ that are clearly nonlinear, confirming that the conditions mentioned above are not fulfilled (Figure S17, Supporting Information).

The methodology reported here does not rely on any of the assumptions listed above, and it only requires a reasonable estimate of the relative values of the HFCCs for the different $\mathrm{Ln}^{3+}$ complexes from DFT calculations performed on the $\mathrm{Gd}^{3+}$ analogue. ${ }^{36}$ Even in the case that the $A / \hbar$ values change considerably across the series, the plots such as those in Figure 3 correct these deviations if the relative values for the different nuclei do not change significantly.

A full set of magnetic anisotropies was reported by Bertini et al. for the $\mathrm{Ln}^{3+}$ ions fixed in a protein matrix. ${ }^{22}$ This approach avoids any contamination of the paramagnetic shifts with contact contributions, which are expected to be important only for nuclei placed a few bonds away from the paramagnetic center. Bertini et al. concluded in that study that the magnetic anisotropies followed reasonably well the predictions of Bleaney's theory. In view of the results reported here, it is clear that, in spite of its usefulness to rationalize the paramagnetic shifts of many series of $\mathrm{Ln}^{3+}$ complexes, Bleaney's theory should be used with care because it might fail even in making qualitative predictions.

The paramagnetic shifts induced by the $\mathrm{Ln}^{3+}$ ions have been used for different applications for more than 40 years. However, some recent studies have witnessed that subtle changes in the $\mathrm{Ln}^{3+}$ coordination environment may provoke drastic changes in the magnetic anisotropies of these ions. For instance, it has been shown that the formation of fluoride dimers with linear Ln-F-Ln bridging units caused dramatic changes in the observed ${ }^{1} \mathrm{H}$ NMR shifts induced by $\mathrm{Yb}^{3+},{ }^{43}$ while the binding of $\mathrm{F}^{-}$to $\mathrm{Ln}^{3+}(\mathrm{DOTA})$ tetraamide complexes provoked a change of the magnetic anisotropy from a prolate to an oblate distribution or vice versa. ${ }^{44}$ The results reported here represent a significant advance for rationalization of the paramagnetic shifts induced by the $\mathrm{Ln}^{3+}$ ions, with a great potential impact for the development of PARASHIFT contrast agents ${ }^{21}$ and the application of paramagnetic $\mathrm{Ln}^{3+}$ ions in NMR spectroscopy of proteins. $^{45}$

\section{Experimental and Computational Section}

\section{NMR Spectroscopy}

${ }^{1} \mathrm{H}$ NMR spectra were recorded at $25{ }^{\circ} \mathrm{C}$ in solutions of the complexes in $\mathrm{D}_{2} \mathrm{O}$ on a Bruker ARX400 spectrometer. Chemical shifts were referenced by using the residual solvent proton signal $(\delta=4.79 \mathrm{ppm}){ }^{46}$

\section{$\underline{\text { Computational Details }}$}

All calculations presented in this work were performed by employing the Gaussian 09 package (revision D.01). ${ }^{47}$ As for the Pr and $\mathrm{Yb}$ complexes reported in our previous work, full geometry optimizations of the $\left[\mathrm{LnL}^{1}\right]^{3+}$ systems $(\mathrm{Ln}=\mathrm{Ce}, \mathrm{Nd}, \mathrm{Eu}, \mathrm{Gd}, \mathrm{Tb}, \mathrm{Ho}, \mathrm{Er}, \mathrm{Tm})$ were performed in aqueous solution employing DFT within the hybrid meta generalized gradient approximation, with the TPSSh exchange-correlation 
functional. ${ }^{48}$ The large-core quasirelativistic effective core potentials (ECPs) and associated [5s4p3d]-GTO basis sets of Dolg and co-workers were used for the lanthanides, ${ }^{49}$ while the ligand atoms were described using the standard $6-31 \mathrm{G}(\mathrm{d}, \mathrm{p})$ basis set. The stationary points found on the potential energy surfaces as a result of the geometry optimizations have been tested to represent true energy minima using frequency analysis. HFCCs of the ligand nuclei in $\left[\mathrm{GdL}^{1}\right]^{3+}$ were computed using the all-electron DKH2 method, as implemented in Gaussian 09, ${ }^{50}$ with the all-electron scalar relativistic basis set of Pantazis and Neese for the $\mathrm{Gd}_{\text {atom }}{ }^{51}$ and the EPR-III basis sets of Barone for $\mathrm{C}, \mathrm{H}, \mathrm{N}$, and $\mathrm{O}$ atoms. ${ }^{52} \mathrm{EPR}-\mathrm{III}$ is a triple- $\zeta$ basis set optimized for the computation of HFCCs that includes diffuse functions, double $d$ polarizations, a single set of f-polarization functions, and an improved s part to better describe the nuclear region. Bulk water solvent effects were included by using the polarizable continuum model, in which the solute cavity is built as an envelope of spheres centered on atoms or atomic groups with appropriate radii. In particular, we used the integral equation formalism ${ }^{53}$ variant, as implemented in Gaussian 09. The universal-force-field ${ }^{54}$ radii scaled by a factor of 1.1 were used to define the solute cavity.

\section{Associated Content}

Supporting Information

The Supporting Information is available free of charge on the ACS Publications website at DOI: 10.1021/acs.inorgchem.5b02918.

- $\quad{ }^{1} \mathrm{H}$ and ${ }^{1} \mathrm{H}-{ }^{1} \mathrm{H}$ COSY NMR spectra, experimental and calculated paramagnetic shifts and contact and pseudocontact contributions, bond distances and optimized geometries obtained with DFT, plots of $\left\langle S_{z}\right\rangle^{\text {eff }}$ versus $\left\langle S_{z}\right\rangle$ and $\left\langle S_{z}\right\rangle^{\text {eff }}$ versus $\mathrm{AF}_{j}$, and complete ref $45(\underline{\mathrm{PDF}})$

\section{Author Information}

\section{Corresponding Author}

*E-mail: $\underline{\text { carlos.platas.iglesias@udc.es. }}$

\section{$\underline{\text { Author Contributions }}$}

The manuscript was written through contributions of all authors. All authors have given approval to the final version of the manuscript.

$\underline{\text { Notes }}$

The authors declare no competing financial interest.

\section{Acknowledgment}

M.R.-F., D.E.-G., and C.P.-I. thank the Ministerio de Economía y Competitividad (Grant CTQ2013-43243P) for generous financial support. L.V. and P.P.-L. thank the Ministerio de Ciencia e Innovación, Plan Nacional de I+D+i (Grant CTQ2011-24487) for financial support. The authors are indebted to Centro de Supercomputación of Galicia for providing the computer facilities. 


\section{References}

(1) (a) Horrocks, W. DeW., Jr.; Sipe, J. P., III J. Am. Chem. Soc. 1971, 93, 6800-6804. (b) Hinckley, C. C. J. Am. Chem. Soc. 1969, 91, 5160-5162.

(2) Geraldes, C. F. G. C. Lanthanide Shift Reagents. In The Rare Earth Elements: Fundamentals and Applications; Atwood, D. A., Ed.; Wiley: Chichester, U.K., 2012. pp 501-520.

(3) (a) Wenzel, T. J.; Wilcox, J. D. Chirality 2003, 15, 256-270. (b) Aspinall, H. C. Chem. Rev. 2002, 102, 1807-1850. (c) Ghosh, I.; Zeng, H.; Kishi, Y. Org. Lett. 2004, 6, 4715-4718.

(4) (a) Gencic, M. S.; Radulovic, N. S. RSC Adv. 2015, 5, 72670-72682. (b) Rachineni, K.; Kakita, V. M. R.; Dayaka, S.; Vemulapalli, S. P. B.; Bharatam, J. Anal. Chem. 2015, 87, 7258-7266.

(5) (a) Yamaguchi, T.; Sakae, Y.; Zhang, Y.; Yamamoto, S.; Okamoto, Y.; Kato, K. Angew. Chem., Int. Ed. 2014, 53, 10941-10944. (b) Barry, C. D.; North, A. C. T.; Glasel, J. A.; Williams, R. J. P.; Xavier, A. V. Nature 1971, 232, 236-245.

(6) (a) Keizers, P. H. J.; Mersinli, B.; Reinle, W.; Donauer, J.; Hiruma, Y.; Hannemann, F.; Overhand, M.; Bernhardt, R.; Ubbink, M. Biochemistry 2010, 49, 6846-6855. (b) Su, X. C.; Liang, H.; Loscha, K. V.; Otting, G. J. Am. Chem. Soc. 2009, 131, 10352-10353. (c) John, M.; Pintacuda, G.; Park, A. Y.; Dixon, N. E.; Otting, G. J. Am. Chem. Soc. 2006, 128, 12910-12916.

(7) (a) Puckeridge, M.; Chapman, B. E.; Conigrave, A. D.; Kuchel, P. W. J. Inorg. Biochem. 2012, 115, 211-219. (b) Buster, D. C.; Castro, M. C. A.; Geraldes, C. F. G. C.; Malloy, C. R.; Sherry, A. D.; Siemers, T. C. Magn. Reson. Med. 1990, 15, 25-32.

(8) The Chemistry of Contrast Agents in Medical Magnetic Resonance Imaging, 2nd ed.; Merbach, A. E., Helm, L., Tóth, E., Eds.; Wiley: New York, 2013.

(9) (a) Aime, S.; Crich, S. G.; Gianolio, E.; Giovenzana, G. B.; Tei, L.; Terreno, E. Coord. Chem. Rev. 2006, 250, 1562-1579. (b) Terreno, E.; Castelli, D. D.; Aime, S. Contrast Media Mol. Imaging 2010, 5, 78-98.

(10) (a) Ratnakar, S. J.; Woods, M.; Lubag, A. J. M.; Kovacs, Z.; Sherry, A. D. J. Am. Chem. Soc. 2008, 130, 6-7. (b) Ratnakar, S. J.; Soesbe, T. C.; Lumata, L. L.; Do, Q. N.; Viswanathan, S.; Lin, C.-Y.; Sherry, A. D.; Kovacs, Z. J. Am. Chem. Soc. 2013, 135, 14904-14907. (c) Zhang, S.; Michaudet, L.; Burgess, S.; Sherry, A. D. Angew. Chem., Int. Ed. 2002, 41, 1919-1921. (d) Viswanathan, S.; Ratnakar, S. J.; Green, K. N.; Kovacs, Z.; De Leon-Rodriguez, L. M.; Sherry, A. D. Angew. Chem., Int. Ed. 2009, 48, 9330-9333. (e) Chauvin, T.; Durand, P.; Bernier, M.; Meudal, H.; Doan, B.-T.; Noury, F.; Badet, B.; Beloeil, J.-C.; Toth, E. Angew. Chem., Int. Ed. 2008, 47, 4370-4372. (f) Liu, G.; Li, Y.; Pagel, M. D. Magn. Reson. Med. 2007, 58, 1249-1256. (g) Zhang, S.; Winter, P.; Wu, K.; Sherry, A. D. J. Am. Chem. Soc. 2001, 123, 1517-1518. (h) Huang, Y.; Coman, D.; Ali, M. M.; Hyder, F. Contrast Media Mol. Imaging 2015, 10, 51-58. (i) Zhang, S.; Merritt, M.; Woessner, D. E.; Lenkinski, R. E.; Sherry, A. D. Acc. Chem. Res. 2003, 36, 783-790. (j) Green, K. N.; Viswanathan, S.; Rojas-Quijano, F. A.; Kovacs, Z.; Sherry, A. D. Inorg. Chem. 2011, 50, 1648-1655. (k) Zhang, S.; Wu, K.; Biewer, M. C.; Sherry, A. D. Inorg. Chem. 2001, 40, 4284-4290.

(11) (a) Aime, S.; Delli Castelli, D.; Terreno, E. Angew. Chem., Int. Ed. 2005, 44, 5513-5515. (b) Ferrauto, G.; Di Gregorio, E.; Baroni, S.; Aime, S. Nano Lett. 2014, 14, 6857-6862.

(12) Harvey, P.; Blamire, A. M.; Wilson, J. I.; Finney, K.-L. N. A.; Funk, A. M.; Senanayake, P. K.; Parker. Chem. Sci. 2013, 4, 4251-4258. 
(13) Forsberg, J. H.; Delaney, R. M.; Zhao, Q.; Harakas, G.; Chandran, R. Inorg. Chem. 1995, 34, 3705-3715.

(14) (a) Peters, J. A.; Huskens, J.; Raber, D. J. Prog. Nucl. Magn. Reson. Spectrosc. 1996, 28, 283-350. (b) Bertini, I.; Luchinat, C.; Parigi, G. Prog. Nucl. Magn. Reson. Spectrosc. 2002, 40, 249-273.

(15) Bleaney, B. J. Magn. Reson. 1972, 8, 91-100.

(16) Terazzi, E.; Rivera, J.-P.; Ouali, N.; Piguet, C. Magn. Reson. Chem. 2006, 44, 539-552.

(17) Piguet, C.; Geraldes, C. Paramagnetic NMR Lanthanide Induced Shifts for Extracting Solution Structures. In Handbook on the Physics and Chemistry of Rare Earths; Gschneidner, K. A., Bunzli, J.-C., Pecharsky, V., Eds.; Elsevier: Amsterdam, The Netherlands, 2003; Vol. 33; pp 353-463.

(18) (a) Ren, J.; Sherry, A.- D. J. Magn. Reson., Ser. B 1996, 111, 178-182. (b) Platas, C.; Avecilla, F.; de Blas, A.; Geraldes, C. F. G. C.; Rodríguez-Blas, T.; Adams, H.; Mahía, J. Inorg. Chem. 1999, 38, 31903199. (c) Rigault, S.; Piguet, C. J. Am. Chem. Soc. 2000, 122, 9304-9305. (d) Ouali, N.; Rivera, J.-P.; Chapon, D.; Delangle, P.; Piguet, C. Inorg. Chem. 2004, 43, 1517-1529.

(19) Mironov, V. S.; Galyametdinov, Y. G.; Ceulemans, A.; Görller-Walrand, C.; Binnemans, K. J. Chem. Phys. 2002, 116, 4673-4685.

(20) Charnock, G. T. P.; Kuprov, I. Phys. Chem. Chem. Phys. 2014, 16, 20184-20189.

(21) Funk, A. M.; Finney, K.-L. N. A.; Harvey, P.; Kenwright, A. M.; Neil, E. R.; Rogers, N. J.; Senanayake, P. K.; Parker, D. Chem. Sci. 2015, 6, 1655-1662.

(22) Bertini, I.; Janik, M. B. L.; Lee, Y.-M.; Luchinat, C.; Rosato, A. J. Am. Chem. Soc. 2001, 123, 4181-4188.

(23) (a) Zhang, P.; Jung, J.; Zhang, L.; Tang, J.; Le Guennic, B. Inorg. Chem. 2016, 55, 1905-1911. (b) Gregson, M.; Chilton, N. F.; Ariciu, A.-M.; Tuna, F.; Crowe, I. F.; Lewis, W.; Blake, A. J.; Collison, D.; McInnes, E. J. L.; Winpenny, R E. P.; Liddle, S. T. Chem. Sci. 2016, 7, 155-165. (c) Brown, A. J.; Pinkowicz, D.; Saber, M. R.; Dunbar, K. R. Angew. Chem., Int. Ed. 2015, 54, 5864-5868. (d) Ishikawa, N.; Sugita, M.; Ishikawa, T.; Koshihara, S.-Y.; Kaizu, Y. J. Am. Chem. Soc. 2003, 125, 8694-8695. (e) Cucinotta, G.; Perfetti, M.; Luzon, J.; Etienne, M.; Car, P.-E.; Caneschi, A.; Calvez, G.; Bernot, K.; Sessoli, R. Angew. Chem., Int. Ed. 2012, 51, 1606-1610.

(24) Woodruff, D. N.; Winpenny, R. E. P.; Layfield, R. A. Chem. Rev. 2013, 113, 5110-5148.

(25) Castro, G.; Regueiro-Figueroa, M.; Esteban-Gómez, D.; Bastida, R.; Macías, A.; Pérez-Lourido, P.; Platas-Iglesias, C.; Valencia, L. Chem.- Eur. J. 2015, 21, 18662-18670.

(26) Di Pietro, S.; Piano, S. L.; Di Bari, L. Coord. Chem. Rev. 2011, 255, 2810-2820.

(27) Aime, S.; Barbero, L.; Botta, M.; Ermondi, G. J. Chem. Soc., Dalton Trans. 1992, 225-228.

(28) Pinkerton, A. A.; Rossier, M.; Spiliadis, S. J. Magn. Reson. 1985, 64, 420-425.

(29) Golding, R. M.; Pyykkö, P. Mol. Phys. 1973, 26, 1389-1396.

(30) Lisowski, J.; Sessler, J. L.; Lynch, V.; Mody, T. D. J. Am. Chem. Soc. 1995, 117, 2273-2285.

(31) Seitz, M.; Oliver, A. G.; Raymond, K. N. J. Am. Chem. Soc. 2007, 129, 11153-11160. 
(32) Regueiro-Figueroa, M.; Esteban-Gómez, D.; de Blas, A.; Rodríguez-Blas, T.; Platas-Iglesias, C. Chem. Eur. J. 2014, 20, 3974-3981.

(33) (a) Willcott, M. R.; Lenkinski, R. E.; Davis, R. E. J. Am. Chem. Soc. 1972, 94, 1742-1744. (b) Davis, R. E.; Willcott, M. R. J. Am. Chem. Soc. 1972, 94, 1744-1745.

(34) Neese, F. Coord. Chem. Rev. 2009, 253, 526-563.

(35) Esteban-Gomez, D.; de Blas, A.; Rodriguez-Blas, T.; Helm, L.; Platas-Iglesias, C. ChemPhysChem 2012, 13, 3640-3650.

(36) Rodriguez-Rodriguez, A.; Esteban-Gomez, D.; de Blas, A.; Rodriguez-Blas, T.; Botta, M.; Tripier, R.; Platas-Iglesias, C. Inorg. Chem. 2012, 51, 13419-13429.

(37) Bertini, I.; Luchinat, C. Coord. Chem. Rev. 1996, 150, 29-75.

(38) Berardozzi, R.; Di Bari, L. Inorg. Chem. 2013, 52, 11514-11518.

(39) Reilley, C. N.; Good, B. W.; Desreux, J. F. Anal. Chem. 1975, 47, 2110-2116.

(40) Valencia, L.; Martínez, J.; Macías, A.; Bastida, R.; Carvalho, R. A.; Geraldes, C. F. G. C. Inorg. Chem. 2002, 41, 5300-5312.

(41) Ouali, N.; Bocquet, B.; Rigault, S.; Morgantini, P.-Y.; Weber, J.; Piguet, C. Inorg. Chem. 2002, 41, $1436-1445$.

(42) Zhang, Y.; Krylov, D.; Rosenkranz, M.; Schiemenz, S.; Popov, A. A. Chem. Sci. 2015, 6, 2328-2341.

(43) Liu, T.; Nonat, A.; Beyler, M.; Regueiro-Figueroa, M.; Nchimi Nono, K.; Jeannin, O.; Camerel, F.; Debaene, F.; Cianférani-Sanglier, S.; Tripier, R.; Platas-Iglesias, C.; Charbonnière, L. J. Angew. Chem., Int. Ed. 2014, 53, 7259-7263.

(44) (a) Blackburn, O. A.; Chilton, N. F.; Keller, K.; Tait, C. E.; Myers, W. K.; McInnes, E. J. L.; Kenwright, A. M.; Beer, P. D.; Timmel, C. R.; Faulkner, S. Angew. Chem., Int. Ed. 2015, 54, 10783-10786. (b) Blackburn, O. A.; Kenwright, A. M.; Beer, P. D.; Faulkner, S. Dalton Trans. 2015, 44, 19509-19517.

(45) Liu, W.-M.; Overhand, M.; Ubbink, M. Coord. Chem. Rev. 2014, 273-273, 2-12.

(46) Fulmer, G. R.; Miller, A. J. M.; Sherden, N. H.; Gottlieb, H. E.; Nudelman, A.; Stoltz, B. M.; Bercaw, J. E.; Goldberg, K. I. Organometallics 2010, 29, 2176-2179.

(47) Frisch, M. J. Gaussian 09, revision D.01; Gaussian, Inc.: Wallingford, CT, 2010.

(48) Tao, J. M.; Perdew, J. P.; Staroverov, V. N.; Scuseria, G. E. Phys. Rev. Lett. 2003, 91, 146401.

(49) Dolg, M.; Stoll, H.; Savin, A.; Preuss, H. Theor. Chim. Acta 1989, 75, 173-194.

(50) (a) Barysz, M.; Sadlej, A. J. J. Mol. Struct.: THEOCHEM 2001, 573, 181-200. (b) Reiher, M. Theor. Chem. Acc. 2006, 116, 241-252.

(51) Pantazis, D. A.; Neese, F. J. Chem. Theory Comput. 2009, 5, 2229-2238.

(52) Rega, N.; Cossi, M.; Barone, V. J. J. Chem. Phys. 1996, 105, 11060-11067.

(53) Tomasi, J.; Mennucci, B.; Cammi, R. Chem. Rev. 2005, 105, 2999-3093. 
(54) Rappe, A. K.; Casewit, C. J.; Colwell, K. S.; Goddard, W. A., III; Skiff, W. M. J. Am. Chem. Soc. 1992, $114,10024-10035$. 